\title{
Effects of Hydrogen Peroxide on Hydroponic Lettuce Grown with Conventional and Organic Fertilizers
}

Vanessa M. Lau \& Neil S. Mattson

Background \& Objectives

With organic agriculture and hydroponics growing in popularity, implementation of both techniques is becoming widespread. Benefits of using organic fertilizers in hydroponics include a lesser environmental impact since

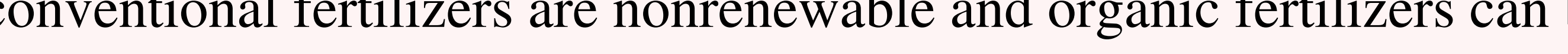
generated from products otherwise directed toward the waste stream. One of biggest detriments to organic hydroponics is that yield tends to be lower than that of its conventional counterpart. This is often attributed to biofilm formation in reservoirs that contains which compete with crops for resources such as oxygen, and nutrients. The biofilm tends to cling to roots limiting dissolved oxygen (DO) availability. Hydrogen peroxide $\left(\mathrm{H}_{2} \mathrm{O}_{2}\right)$ is a disinfectant that decomposes to form oxygen $\left(\mathrm{O}_{2}\right)$ and water $\left(\mathrm{H}_{2} \mathrm{O}\right)$, therefore it may control biofilm and increase DO, but it could also damage plant roots. The objective of this experiment was to determine the effects of $\mathrm{H}_{2} \mathrm{O}_{2}$ as a disinfectant to increase crop yield for conventional or organic fertilizers. A second objective was to determine the effect of $\mathrm{H}_{2} \mathrm{O}_{2}$ on DO

\section{Methodology}

The experiment was conducted in a glass greenhouse at room temperature and with ambient light. Three different treatments consisting of a control, 1.25 $\mathrm{mL} / \mathrm{L}$, and $2.5 \mathrm{~mL} / \mathrm{L}$ of $\mathrm{H}_{2} \mathrm{O}_{2}$ were added to aerated 4-L deep water culture reservoirs that were fertilized with either organic (4-4-1, Drammatic One fish emulsion) or inorganic nutrients (21-5-20), both applied at $150 \mathrm{mg} / \mathrm{L} \mathrm{N}$. Three replicates for each treatment and each fertilizer were prepared resulting in a total of eighteen

Each day, EC was adjusted and maintained between $1.5-1.7 \mathrm{mS} / \mathrm{cm}$, $\mathrm{pH}$ was kept between 5.5-6.0, and dissolved oxygen levels were recorded. Every three days, $\mathrm{H}_{2} \mathrm{O}_{2}$ treaments were reapplied and plant height, leaf length, and root length were measured. At the end of the experiment, fresh weight of the lettuce leaves were recorded.

Final Lettuce Fresh Weight

Organically Fertilized Chemically Fertilized

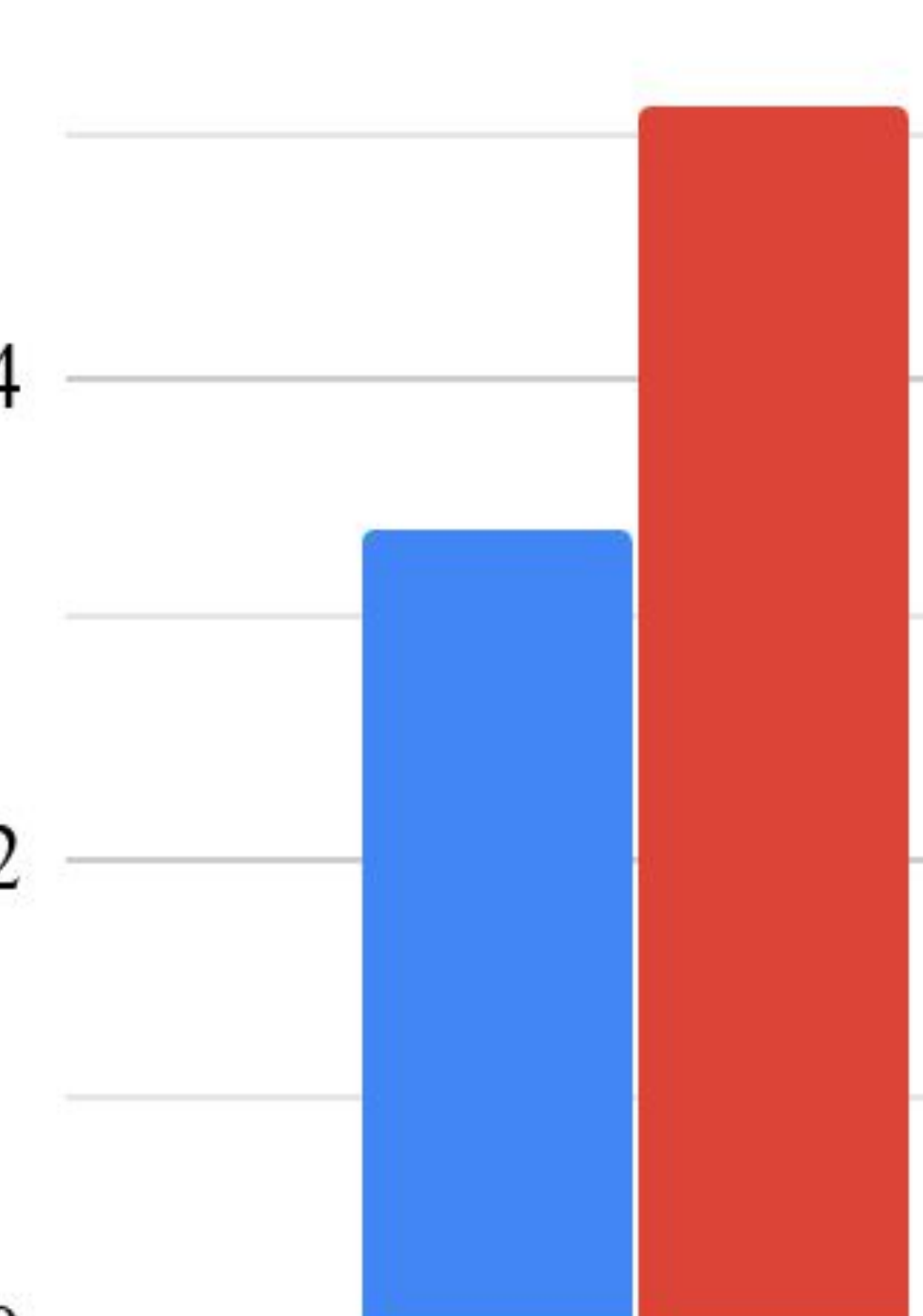

Control

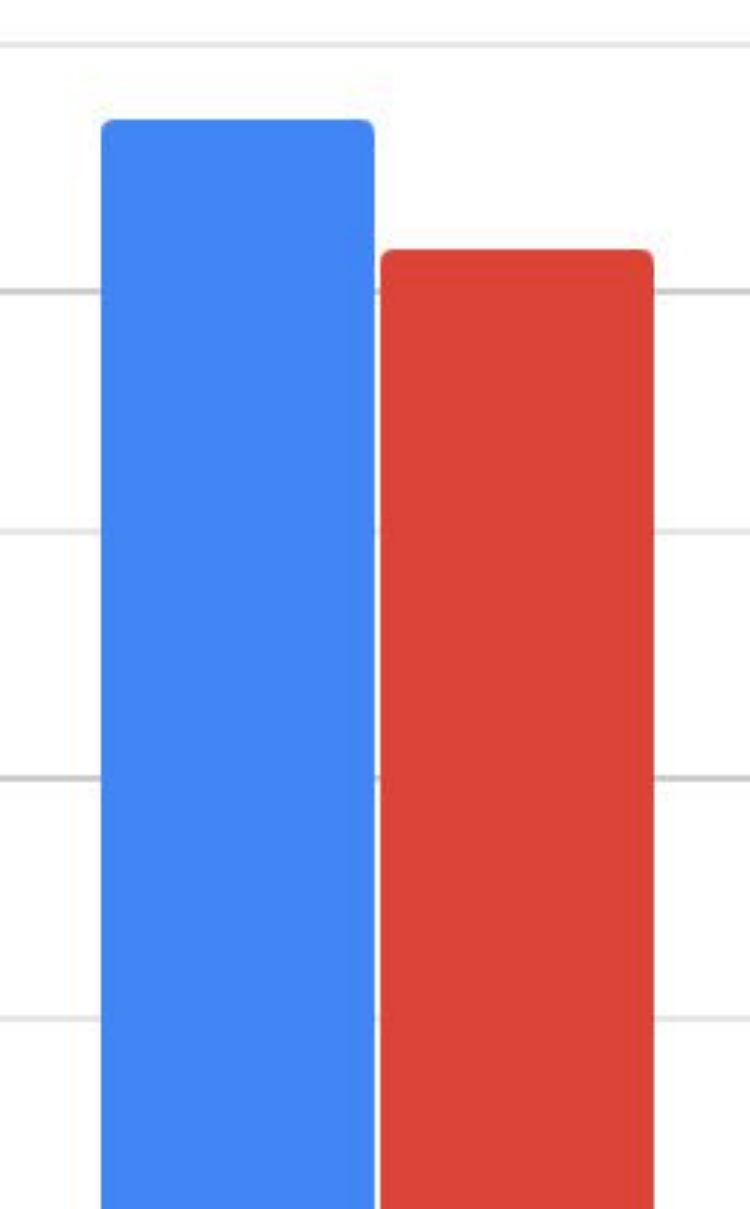

$1.25 \mathrm{~mL} / \mathrm{L}$

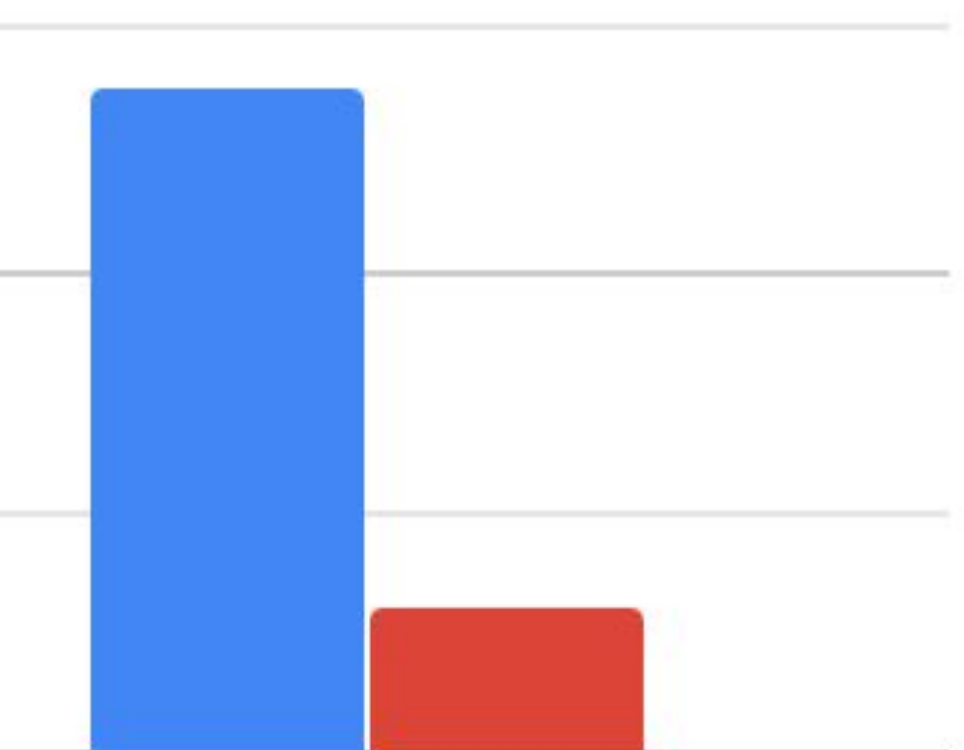

$2.5 \mathrm{~mL} / \mathrm{L}$
Department of Horticulture, Cornell University, Ithaca, NY 14853

\section{Dissolved Oxygen Measurements}

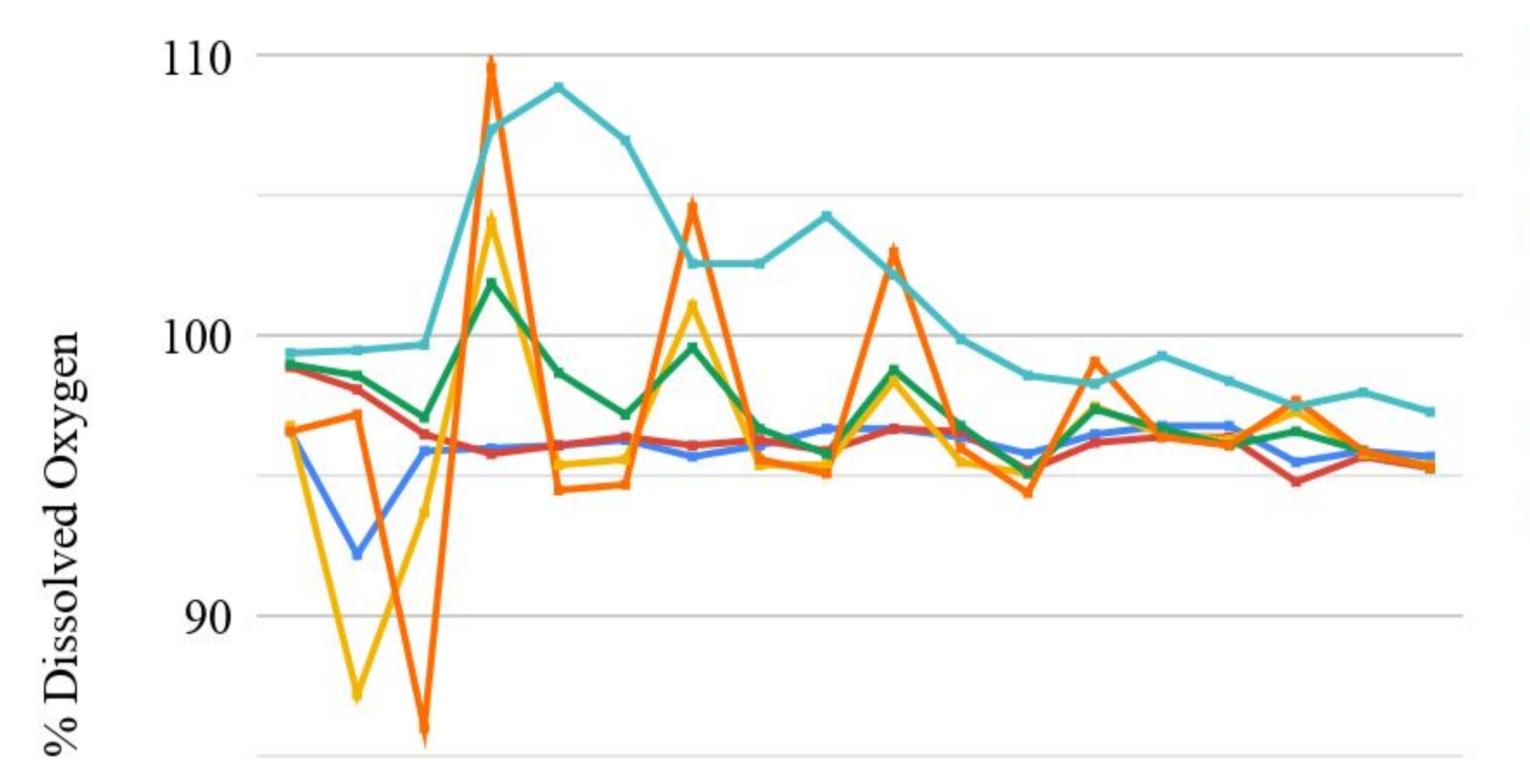

- Organic Control

- Chemical Control

- Organic $1.25 \mathrm{~mL} / \mathrm{L}$

- Chemical $1.25 \mathrm{~mL} / \mathrm{L}$

Organic $2.5 \mathrm{~mL} / \mathrm{L}$

- Chemical $2.5 \mathrm{~mL} / \mathrm{L}$

80

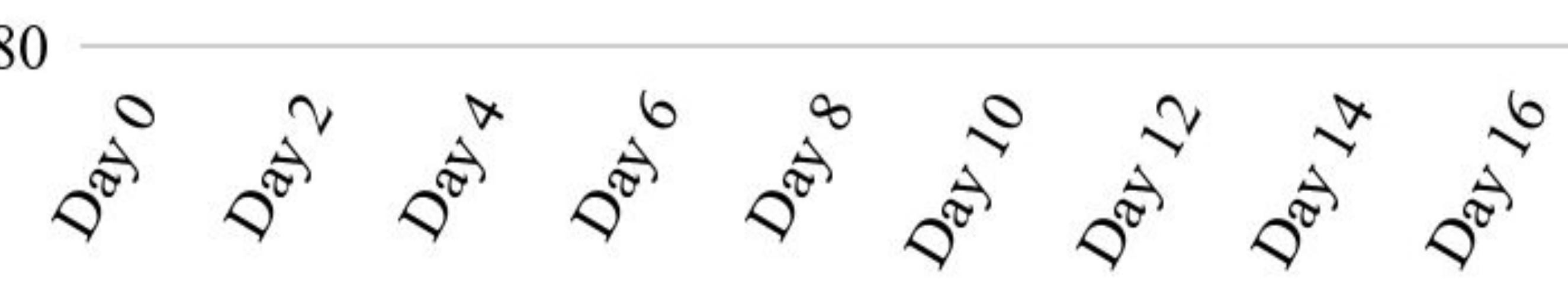

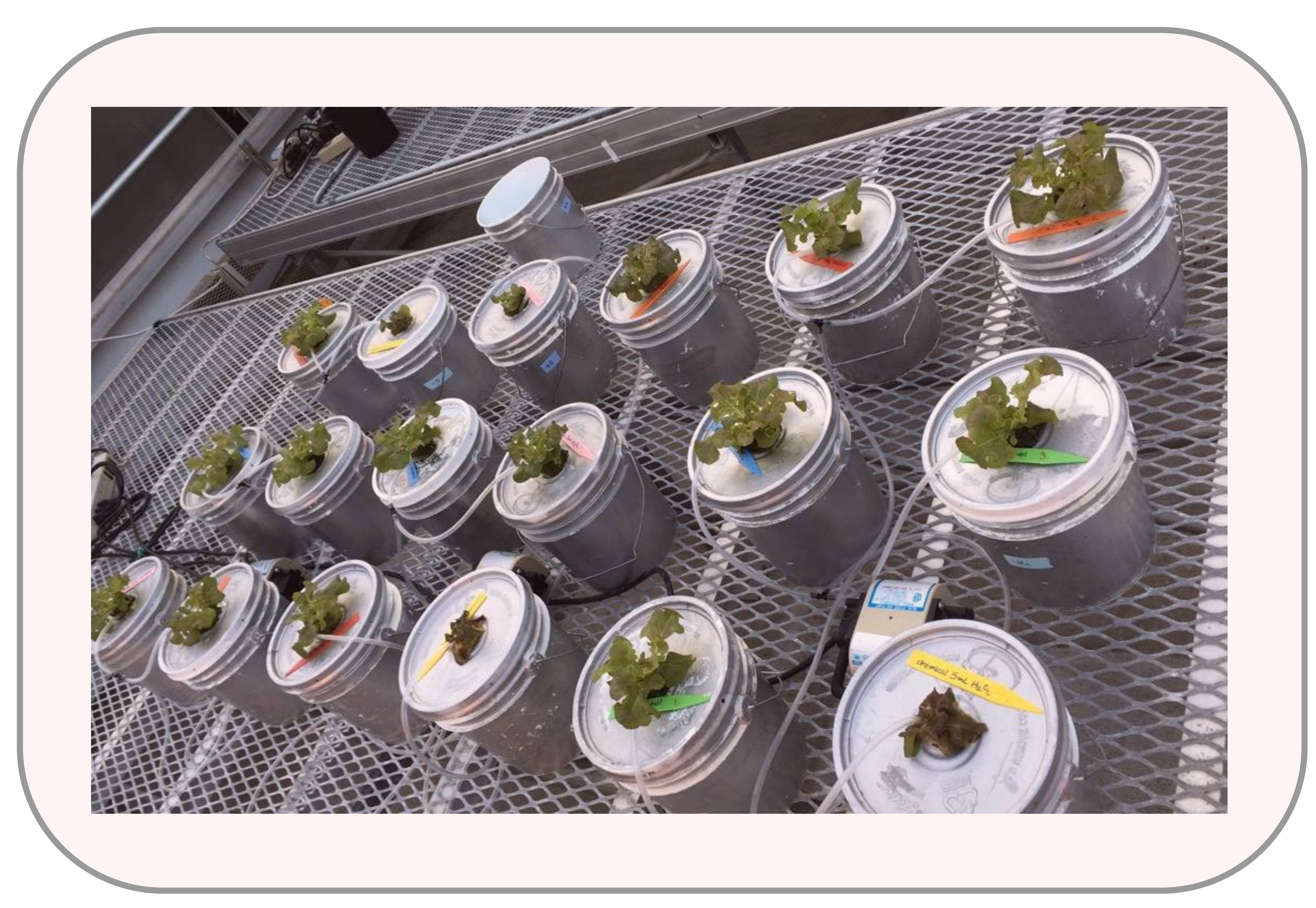

\section{Results \& Discussion}

While it was predicted that all of the reservoirs treated with hydrogen peroxide would yield larger, more robust lettuce heads, that was not the case. The results of this trial showed that when added to conventional fertilizers, doses of $1.25 \mathrm{~mL} / \mathrm{L}$ and $2.5 \mathrm{~mL} / \mathrm{L}$ of $\mathrm{H}_{2} \mathrm{O}_{2}$ stunted the growth of or wilted the heads of lettuce, respectively. However, when applied to organic fertilizers, doses of $1.25 \mathrm{~mL} / \mathrm{L} \mathrm{H} \mathrm{H}_{2} \mathrm{O}_{2}$ significantly increased yield almost matching that of the conventionally fertilized control. But at a dose of $2.5 \mathrm{~mL} / \mathrm{L} \mathrm{H}_{2} \mathrm{O}_{2}$ on organic treatments, growth was also stunted. Though some biofilm visibly persisted, no diseases developed in the root zones and though the addition of $\mathrm{H}_{2} \mathrm{O}_{2}$ seems to have negatively impacted root development, the effects on conventionally fertilized treatments were much greater.

The biweekly addition of $\mathrm{H}_{2} \mathrm{O}_{2}$ to hydroponic reservoirs spiked dissolved oxygen levels upon application, but quickly declined in the following days. As time went on, dissolved oxygen levels seemed to stabilize and $\mathrm{H}_{2} \mathrm{O}_{2}$ treatments had lessened effects.

\section{Conclusion}

This experiment showed that in low doses, the addition of $\mathrm{H}_{2} \mathrm{O}_{2}$ increased the overall yield of organically fertilized hydroponic oakleaf lettuce but was detrimental to the growth of conventionally fertilized treatments. Future trials will be able test different concentrations of $\mathrm{H}_{2} \mathrm{O}_{2}$ to find an optimal dosage and application rate to see if organically fertilized hydroponic lettuce hydroponics more desirable and efficient.

$\mathrm{H}_{2} \mathrm{O}_{2}$ at the applied dosage/frequency was inefficient at clearing biofilm and con contrealate with yield. The primary benefit of $\mathrm{H}_{2} \mathrm{O}_{2}$ may be in increasing DO
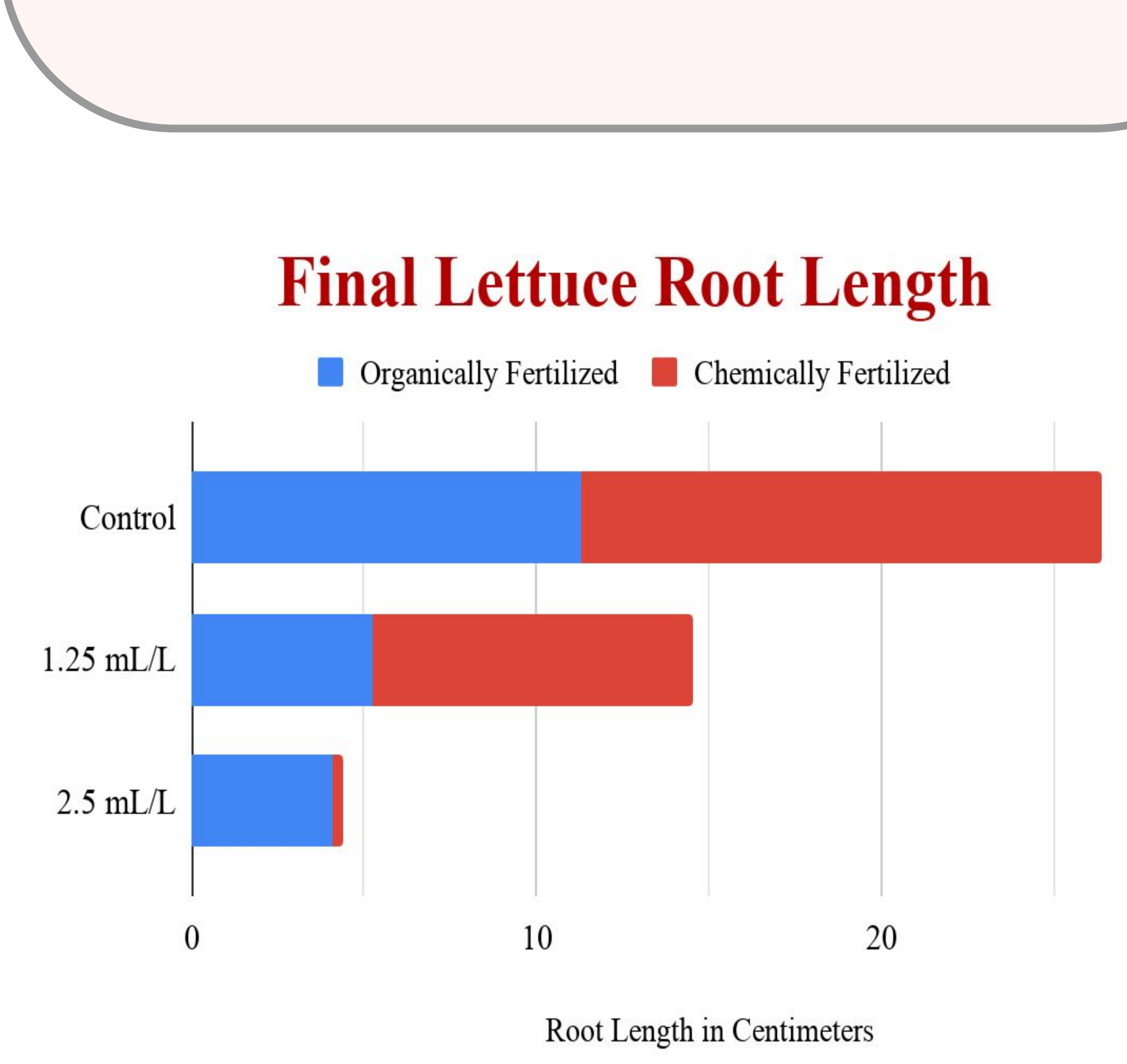